\title{
The role of the geologic substrate on Tillandsia recurvata infestation and the development of forest decaying on a semiarid oak forest
}

\author{
Ulises Rodríguez-Robles ${ }^{1}$ and J. Tulio Arredondo ${ }^{2}$ \\ ${ }^{1}$ Universidad de Guadalajara Centro Universitario de la Costa Sur \\ ${ }^{2}$ Instituto Potosino de Investigacion Cientifica y Tecnologica
}

November 20, 2020

\begin{abstract}
The Geodiversity involves substrate characteristics such as degree of fractured rock, fracture depth, soil depth, parental rock, soil texture, etc., that affect the hidrology of substrates and subsequently the availability of water for plants. Here we examined the importance of the geological substrate, as a factor that triggers the incidence of forest decline. We demonstrated that characteristics of the geological substrate related to the limitation of water availability enhances Tillandsia recurvata (Tire) infestation and eventually causes loss of vigor in oak trees. Using electrical resistivity tomography (geophysical methods) and stable isotope techniques $(\delta 18 \mathrm{O} / \delta 16 \mathrm{O})$, we showed that substrates dominated by regolith and rocks imposed greater conditions of drought to an oak forest stand than a substrate with a more granulated material. Trees in this forest stand presented greater densities of Tire, a plant considered as epiphyte. However, under the observed conditions of high infestation, Tire apparently exhibited a change from epiphytic to parasitic plant as it acquired water from oak. This study identified that the structural composition of the substrate (i.e. geodiversity) is a factor accelerating the processes of decay and likely forest mortality related to the effects of drought and the infestation by pests and diseases.
\end{abstract}

\section{Hosted file}

manuscript tree and forest mortality PC\&E.pdf available at https://authorea.com/users/310161/ articles/494133-the-role-of-the-geologic-substrate-on-tillandsia-recurvata-infestationand-the-development-of-forest-decaying-on-a-semiarid-oak-forest
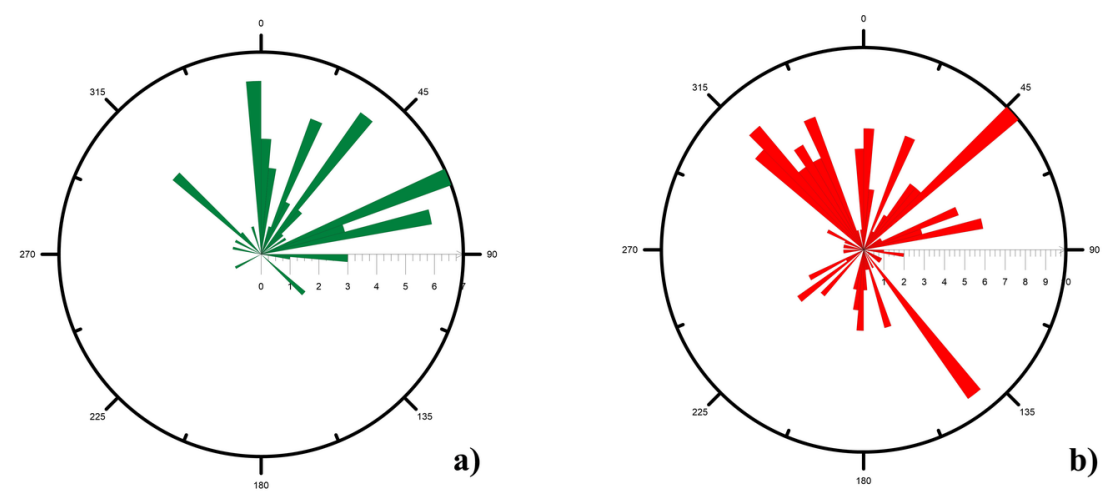
Rainy season (Jun - Oct 2016)
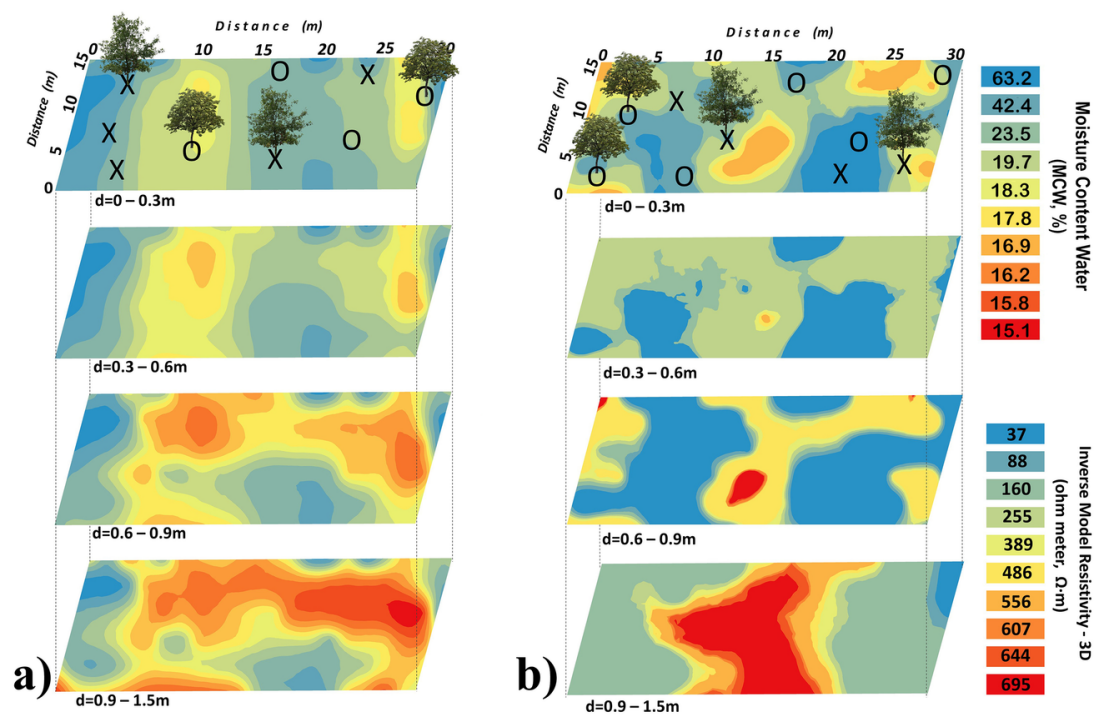

Dry season (Nov 16 - May 17)
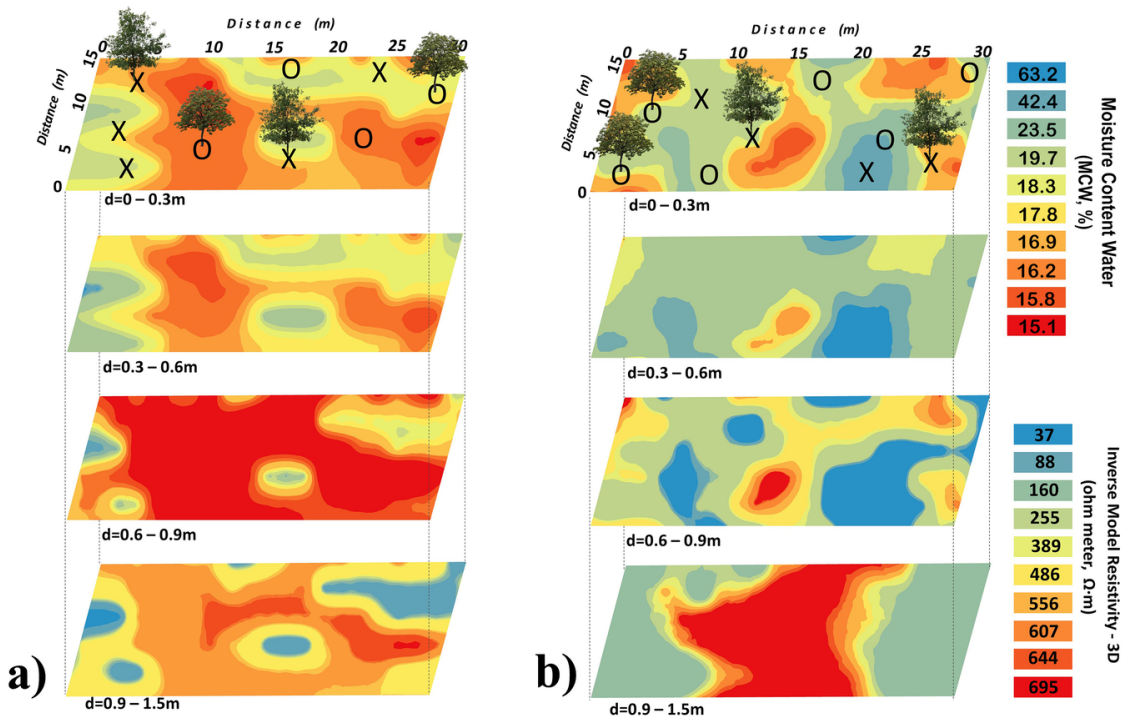


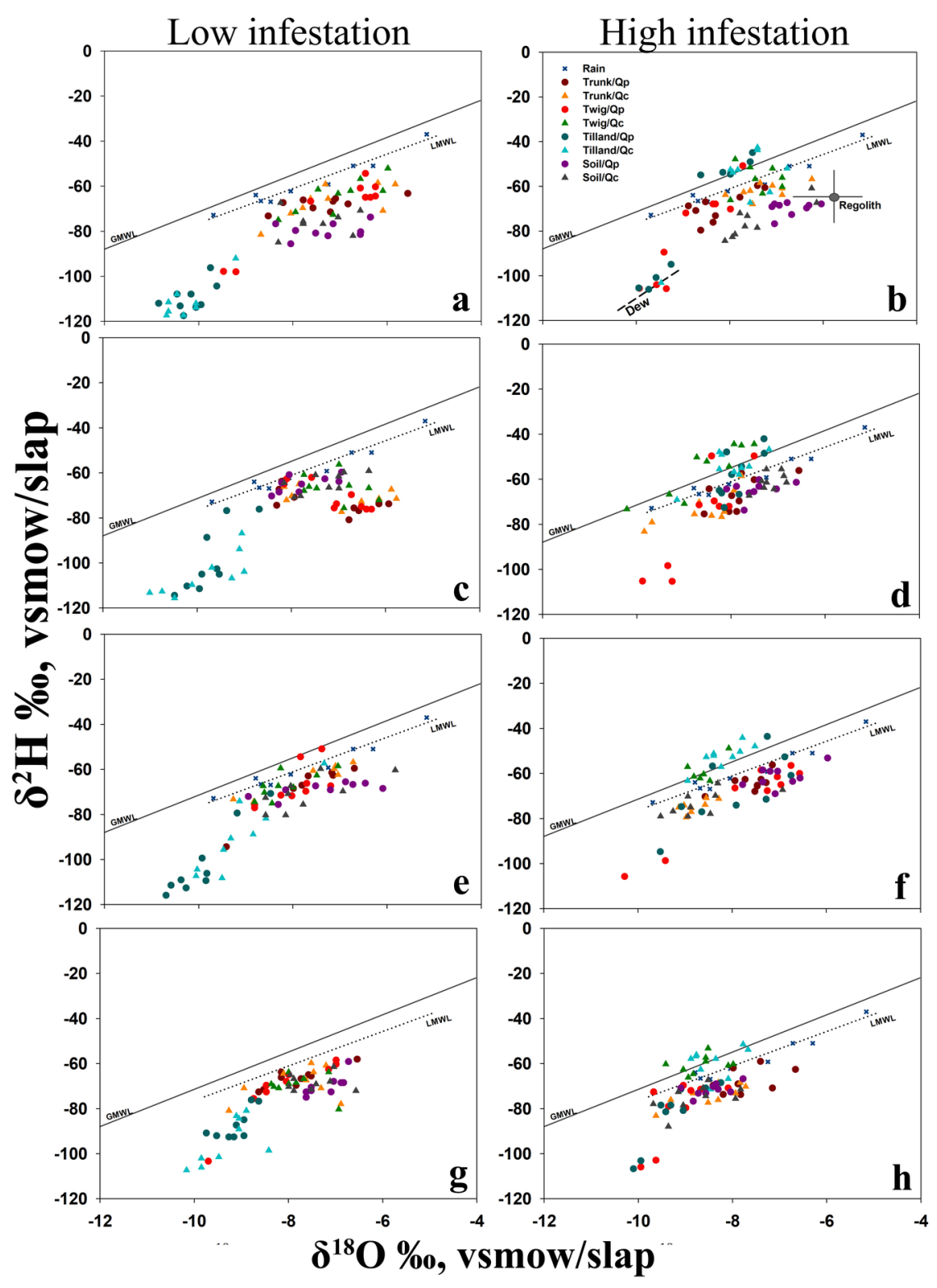




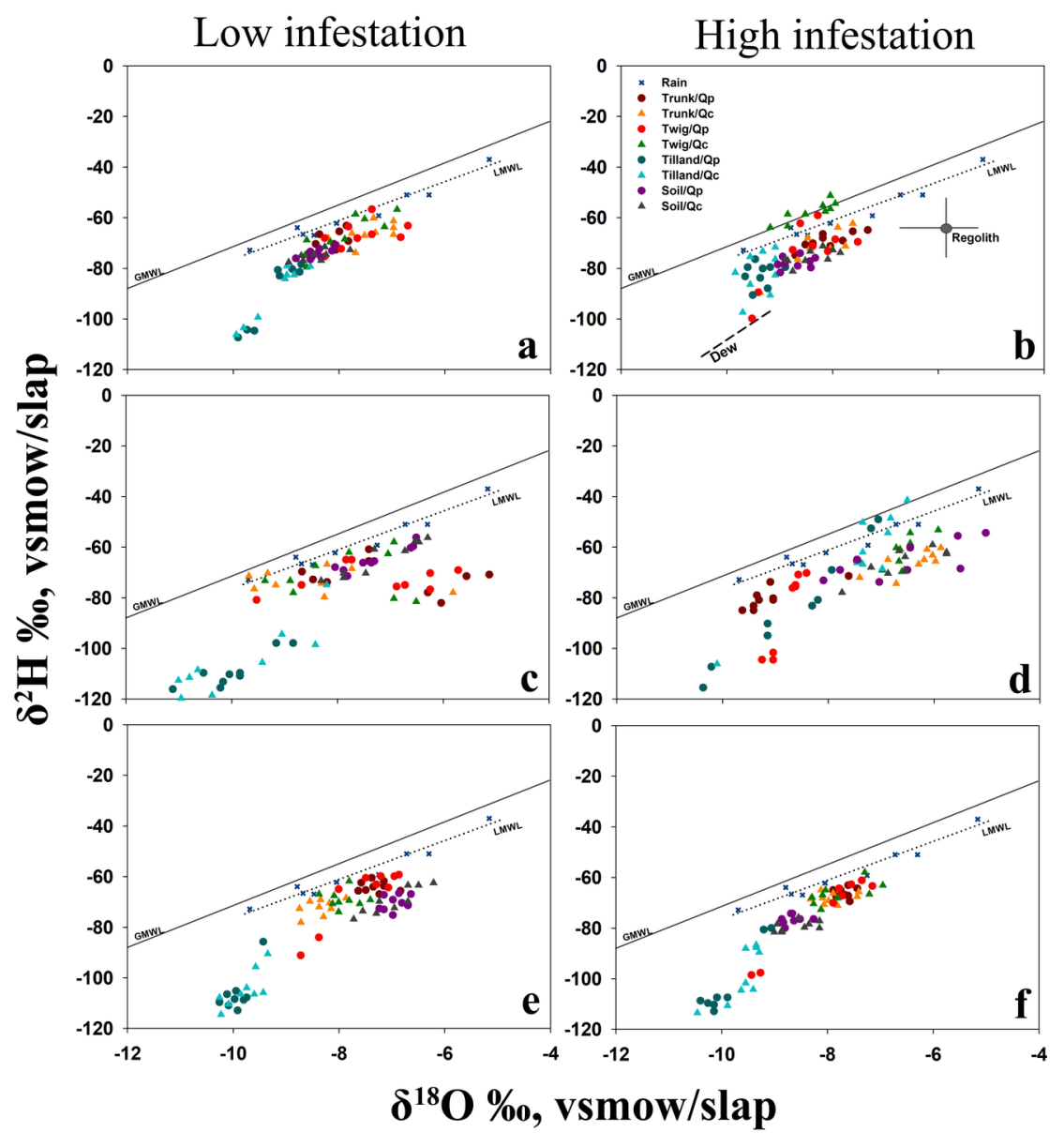




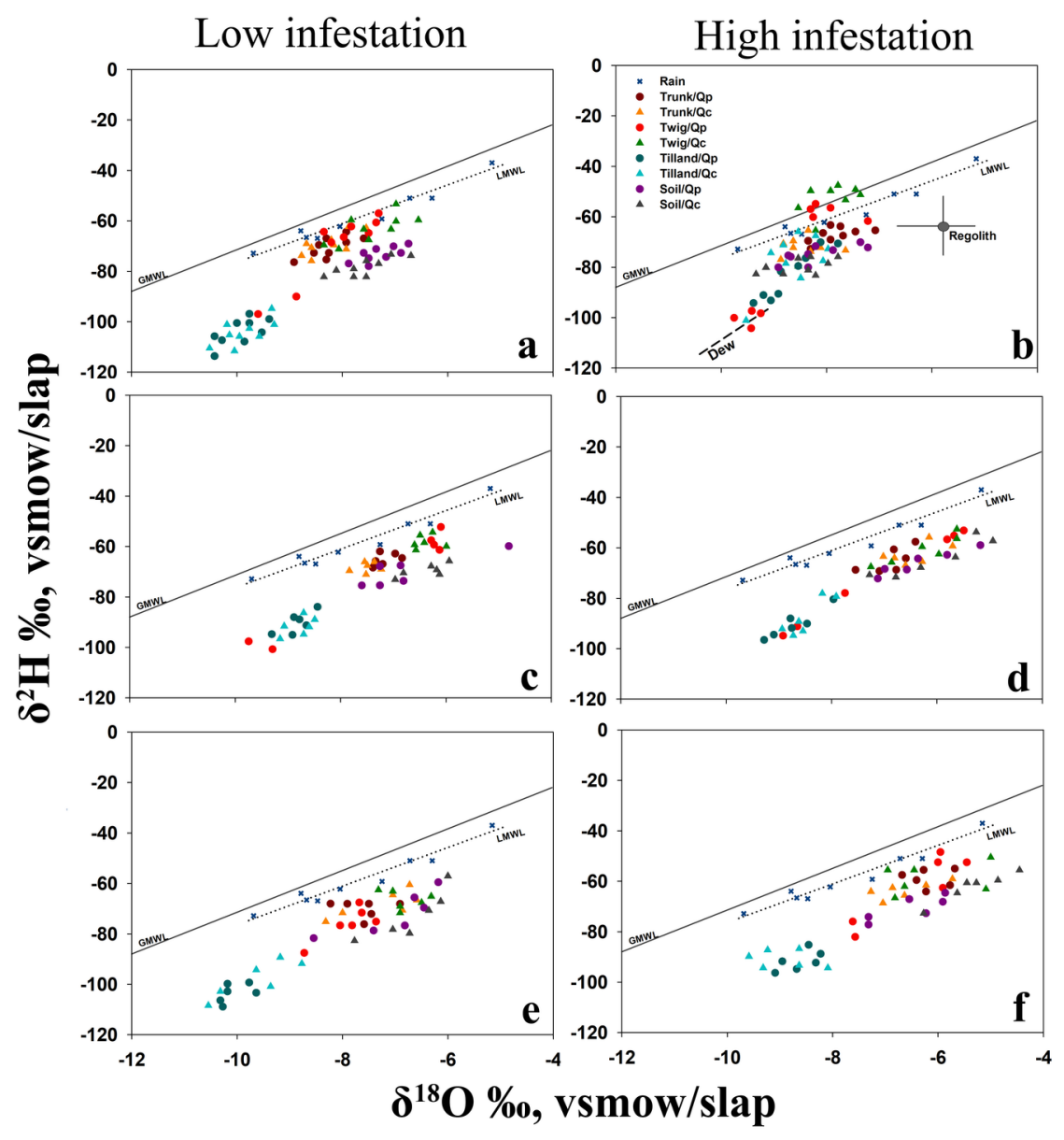




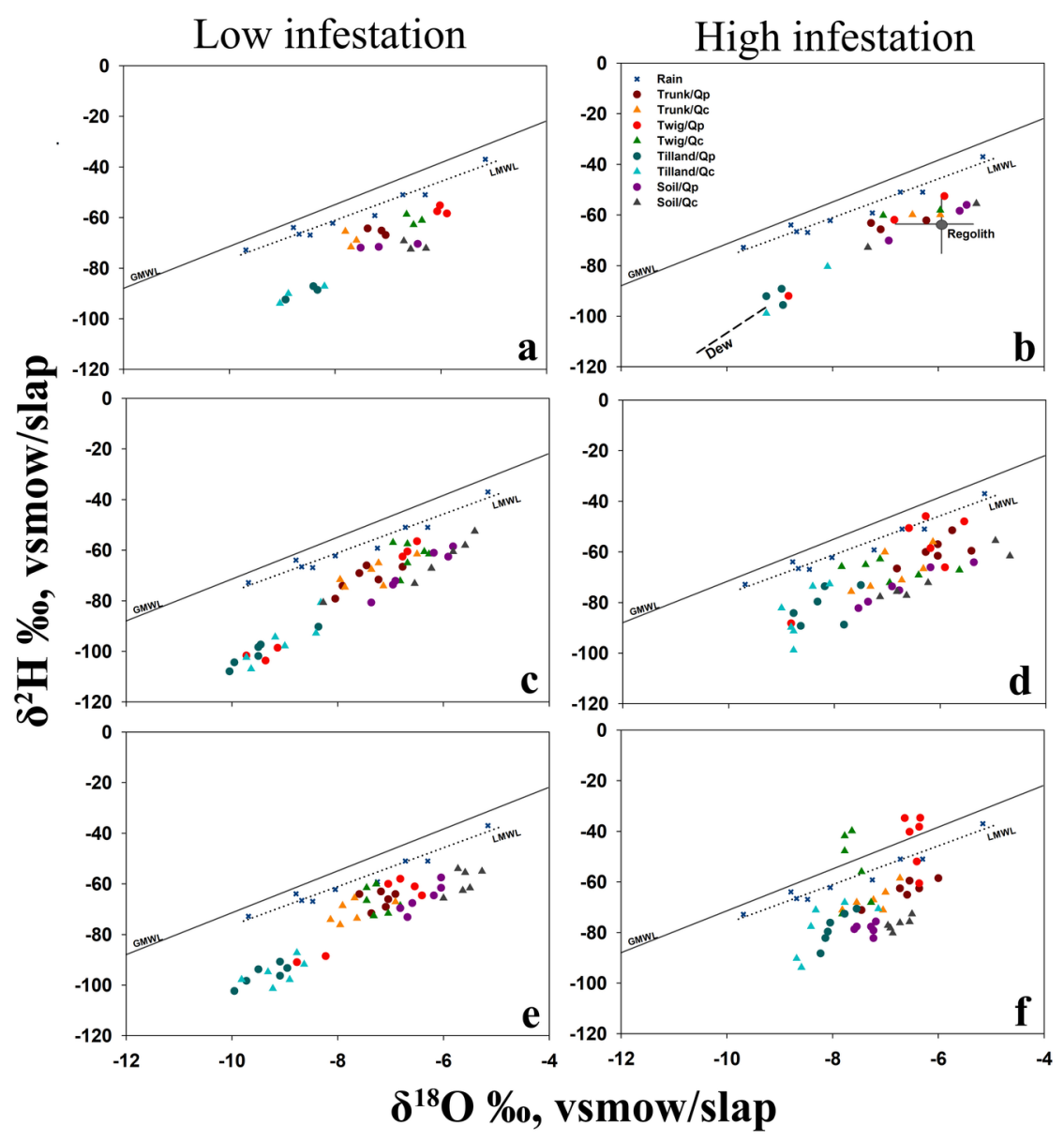




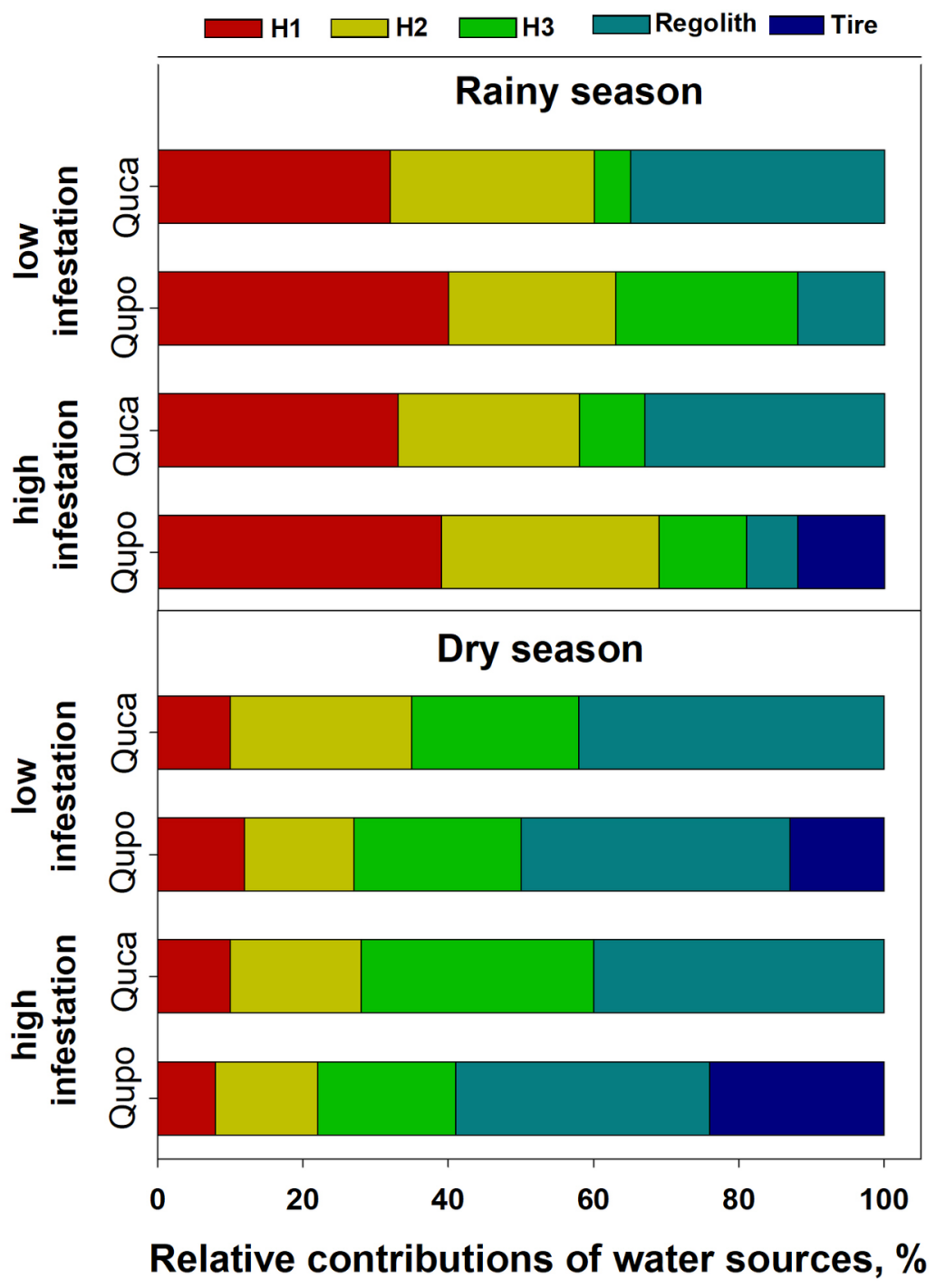




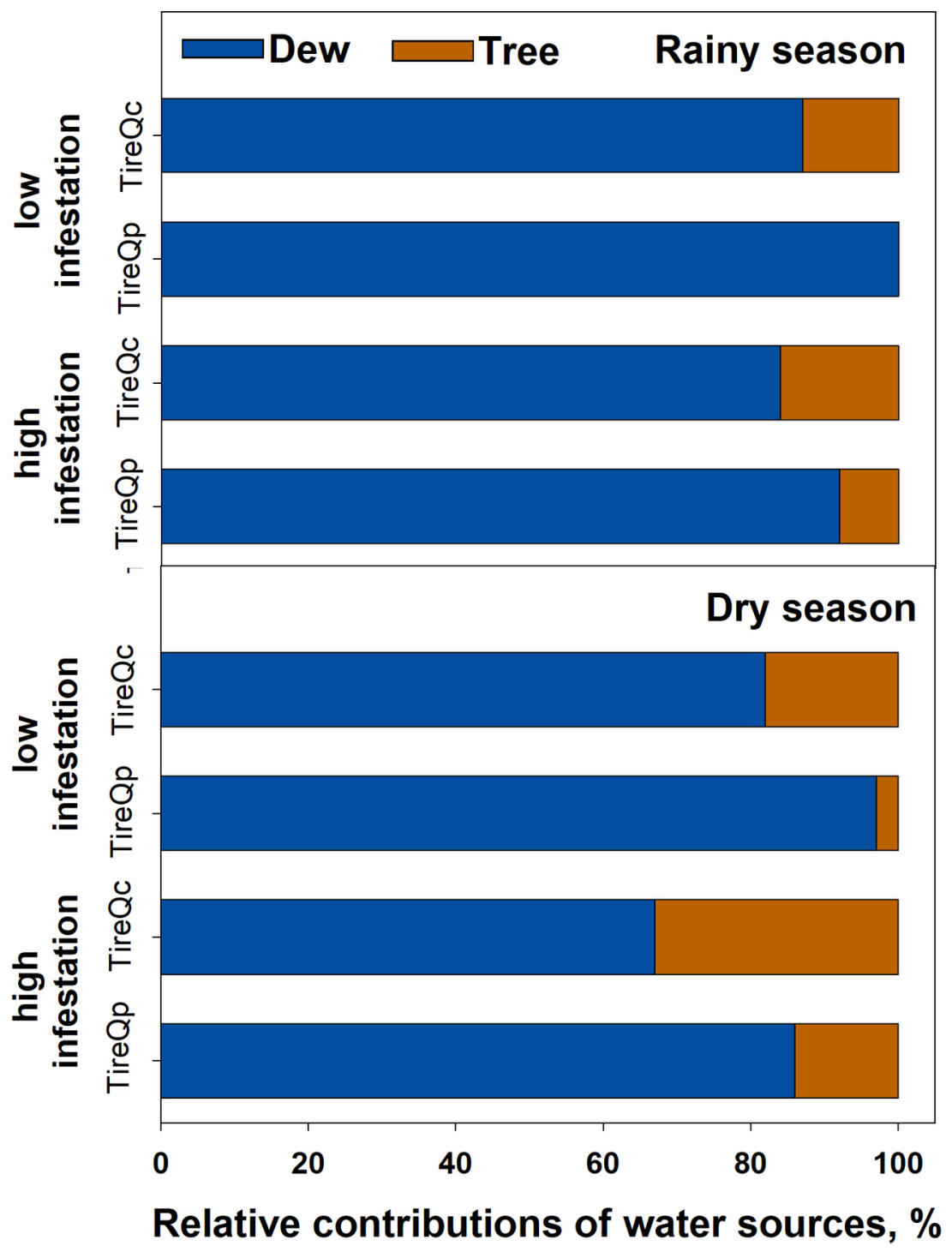

